\title{
The Role of Bcl-2, CD10 and CD34 Expression in Differentiation between Basal Cell Carcinoma and Trichoepithelioma
}

\author{
Sayed Abdel Raheem, Rabee Alsahaer, Alsayed Tealeb, Emad Rushdy \\ Pathology Department, Faculty of Medicine, Al-Azhar University, Cairo, Egypt \\ Email: sayedabdelrahim8@gmail.com
}

Received 12 March 2014; revised 12 April 2014; accepted 10 May 2014

Copyright (C) 2014 by authors and Scientific Research Publishing Inc.

This work is licensed under the Creative Commons Attribution International License (CC BY). http://creativecommons.org/licenses/by/4.0/

(c) (i) Open Access

\section{Abstract}

Background: Basal cell carcinoma (BCC) and trichoepithelioma (TE) have some similarities clinically and histologically. The aim of this work is to evaluate the role of Bcl-2, CD10 and CD34 in differentiation between BCC and TE. Methods: The immunohistochemical expression of Bcl-2, CD10 and CD34 was evaluated in 20 BCCs and 12 TEs in a retrospective study. The localization of these markers in tumor and stromal cells was determined and comparison between BCC and TE was done. Immunohistochemistry for Bcl-2, CD10 and CD34 was performed on sections obtained from formalin-fixed, paraffin-embedded blocks. Bcl-2, CD10 and CD34 immunoreactivity in the stromal and/or tumor cells was determined as follows: negative (0); $1+(10 \%-50 \%$ positive cells $)$; and $2+$ ( $>50 \%$ positive cells). Results: In BCC ( 20 cases), the expression of Bcl-2 in stromal cells showed (0) immunoreactivity in 8 cases $(40 \%),(1+)$ immunoreactivity in 7 cases $(35 \%)$, and $(2+)$ immunoreactivity in 5 cases $(25 \%)$. Tumoral cells showed diffuse positivity in 20 out of 20 cases (100\%), $(1+)$ immunoreactivity in 5 cases $(25 \%)$ and $(2+)$ immunoreactivity in 15 cases $(75 \%)$. On the other hand, the expression of Bcl2 in TE, 4 cases showed positive stromal cells out of $12(33.33 \%)$, (1+) immunoreactivity in 2 cases $(16.6 \%)$ and $(2+)$ immunoreactivity in 2 cases $(16.6 \%)$, and 8 cases showed no immunoreactivity. Tumoral cells showed positivity in 12 out of 12 cases (100\%), $(1+)$ immunoreactivity in 5 cases $(41.6 \%),(2+)$ immunoreactivity in 7 cases (58.3\%). In BCC cases, the expression of CD10 was noted in stromal cells in 8 out of 20 cases $(40 \%), 5$ cases showed positivity in stromal and basaloid cells and 3 cases showed positivity in stromal cells only, and 12 cases showed no immunoreactivity (60\%). Tumor cells showed positivity in 11 cases out of 20 (55\%), (1+) immunoreactivity in 6 cases $(30 \%),(2+)$ in 5 cases $(25 \%)$, and 9 cases showed no immunoreactivity (45\%). On the other hand, the expression of CD10 in TE 7 cases showed positive stromal cells out of $12(58.33 \%),(1+)$ immunoreactivity in 5 cases $(41.6 \%)$ and $(2+)$ in 2 cases $(16.6 \%)$, and 5 cases showed no immunoreactivity $(41.66 \%)$. Tumor cells showed positivity in 5 cases out of $12(41.66 \%),(1+)$ immunoreactivity in 4 cases $(33.33 \%)$ and $(2+)$ in 1 case $(8.3 \%)$, and 7 cases showed no immunoreactivity (58.33\%). In BCC cases, the expression of CD34 was noted in stromal 
cells in14 cases out of 20 cases $(70 \%),(1+)$ immunoreactivity in 10 cases $(50 \%)$ and $(2+)$ in 4 cases $(20 \%)$, and 6 cases showed no immunoreactivity (30\%). On the other hand, the expression of CD34 in TE, 10 cases showed positive stromal cells out of $12(83.33 \%),(1+)$ immunoreactivity in 6 cases $(50 \%)$ and $(2+)$ in 4 cases $(33.33 \%)$, and 2 cases showed no immunoreactivity $(16.6 \%)$. Tumor cells showed no immunoreactivity for CD 34 in both BCC and trichoepithelioma, (100\%) negative tumor cells. Significant difference of tumor $\backslash$ stromal cells immunoreactivity for Bcl-2 and CD34 in both BCC and TE but it was insignificant for CD10. Conclusion: We conclude that Bcl-2 CD10, CD34 are useful markers in the differential diagnosis of BCC versus TE.

\section{Keywords}

Basal Cell Carcinoma, Trichoepithelioma, Bcl-2, CD10, CD34

\section{Introduction}

Basal cell carcinoma (BCC) is the most common cutaneous tumor, accounting for approximately $70 \%$ of all malignant diseases of the skin. It is locally aggressive and its metastasis is unusual [1]. Immunohistochemical studies support the notion that BCC originates from the basaloid epithelium of follicular bulges in the anagen hair bulbs and the follicular matrix cells [2]. Trichoepithelioma (TE) is a benign skin tumor with follicular differentiation [3]. Differential diagnosis between TE, trichoblastoma, trichofolliculoma, trichoadenoma, and BCC may be very difficult for the clinician and the pathologist [4]. Histologically, both BCC and TE are composed of nests of basaloid cells within the dermis, although these differences are distinguishable in the majority of cases [5]. CD10 is identified as the common acute lymphoblastic leukemia antigen, or CALLA [6]. CD10 may be useful for the differential diagnosis between benign tumors of cutaneous appendages originating from the hair follicle and BCC and it may solve a dilemma for the clinician and the pathologist, particularly in small and superficial biopsies [4]. Furthermore, CD10 expression can be detected in the peritumoral fibroblast-like stromal cells within the invasive area of various cancers such as prostate, breast, colorectal, and lung carcinomas [7]. CD10 expression exhibits a link with the growth rate of the cells. Its expression is increased in malignant tumors and regenerating tissues [8]. Bcl-2 is an anti-apoptotic protein residing on the outer mitochondrial membrane. It is implicated in the pathogenesis of several common cancers by inhibiting programmed cell death. In normal skin, Bcl-2 stains the majority of keratinocytes in the basal epidermis, cells of the outer root sheath (ORS), mesenchymal cells of the follicular papillae, and clear cells of eccrine glands [9]. Diffuse cytoplasmic Bcl-2 expression is reported in BCC [9] [10], and is reported to be useful in the distinction of BCC (diffuse staining) from TE (staining of basal layer only) [11], and in the distinction of BCC from solar keratosis (latter negative) [12]. CD34 is an intercellular adhesion protein and cell surface glycoprotein expressing in the immature hematopoietic cells and endothelial cells. CD34 is expressed in endothelial cells of the normal skin, perivascular interstitial dendritic cells of reticular dermis, around the hair follicle, and spindle cells in basal membrane zones of eccrine glands [13]-[15].

\section{Material and Methods}

This study involved 32 cases; 20 cases of BCC and 12 cases of trichoepithelioma retrieved from the archives of the histopathology lab of Al Azhar University hospitals. The age, sex and site of lesions were recorded. From each paraffin block, four sections (5 micron each) were prepared for routine hematoxyllin and eosin (H\&E), Bcl-2, CD10 and CD34 immunostaining. Sections stained by H\&E were examined to detect pattern of growth. Sections that were immunostained for Bcl-2, CD10 and CD34 were examined microscopically to detect positively-stained tumor cells. Positive cells were considered according to (Yada et al., 2004) [16]. Reactivity of the tumor cells was analyzed for central and/or peripheral staining. Positive CD10 staining was identified as brown cytoplasmic staining with or without cell membrane staining. CD10 expression was compared with the positive control (perifollicular or perisebaceous gland area). Bcl-2 positivity was considered as diffuse cytoplasmic. Bcl-2 staining was compared with positive keratinocytes in the basal epidermis and cells of the outer root sheath (ORS). CD34 positivity was considered as cytoplasmic staining and positivity was compared with positive en- 
dothelial cells of blood vessels of the normal skin, Normal intestinal biopsy and normal tonsils were used as positive control for CD10 and CD34 respectively.

\section{Evaluation and Statistical Analysis}

All specimens were examined under a light microscope and the amount of immunupositive tumor cells and stromal cells were evaluated by using a scale of [0] to [2+] as follows: [0], negative ( $<10 \%$ positive cells); [1+] ( $10 \%$ - $50 \%$ positive cells); [2+] ( $>50 \%$ positive cells).

The data were collected, tabulated, and statistically analyzed, using Statistical Package for the Social Sciences (SPSS). The Fisher exact and Chi-square tests were employed for comparison between the nominal variables, and the Mann-Whitney U test was used to compare the ordinal variables. A P value less than 0.05 were considered significant for all the tests.

\section{Results}

The patients with BCC were comprised of 7 females (35\%) and 13 males (65\%), ranging in age from 35 - 87 years. All of the BCC cases (20) were localized in the head region, 12 cases of TE 5 males (41.66\%) 7 females (58.34\%) ranging in age from 33 - 60 years. 11 cases were localized in the face and 1 one in nape area.

\subsection{Histopathological Findings}

\subsubsection{TE (12 Cases)}

The two major components are horn cysts of varying sizes and basaloid epithelial islands, lacking the retraction artifact typical of basal cell carcinoma. The walls of the horn cysts are formed by a few layers of cells. Some of the basophilic islands resemble follicular papillae (Figure 1).

\subsubsection{BCC (20 Cases)}

Nodular (8 cases; $\mathbf{4 0} \%$ ) characterized by variable-sized nodules of basaloid tumor cells with elongated hyperchromatic nuclei and scant cytoplasm, peripheral palisading and clefts between tumor and surrounding stroma (Figure 2). One case was presented as pigmented nodule.

Superficial (6 cases; $30 \%$ ), buds and irregular proliferations of tumor tissue attached to the undersurface of the epidermis, with clefts at the interface with the dermis.

Adenoid cystic (3 cases; 15\%), show a cribriform or pseudoglandular architecture (usually with an overall nodular growth pattern) associated with mucinous stroma.

Infiltrative (3 cases; 15\%), with more atypia and the infiltrating cords of basaloid cells are slender and widely infiltrative, consistent with the so-called morpheic variant of basal cell carcinoma.

\subsection{Immunohistochemical Findings}

Stromal and tumor cells (peripheral and/or central) expression of Bcl2, CD10 and CD34 was graded from [0] to $[2+]$ as seen in Table 1 for BCC \& Table 2 for TE.

A comparison of Bcl-2, CD10 and CD34 expression between the BCC and TE groups is displayed in Table 3 \& Table 4 and that of Bcl2 in both lesions in Table 5, and that of CD10 in both lesions in Table 6, and that of CD34 in both lesions in Table 7.

\section{Table 1. Expression of CD10, Bcl-2 and CD34 in BCC.}

\begin{tabular}{|c|c|c|c|c|c|c|c|c|c|c|c|c|}
\hline \multirow{2}{*}{$\begin{array}{c}\text { BCC } \\
\text { Immuno reactivity }\end{array}$} & \multicolumn{4}{|c|}{ Bcl-2 } & \multicolumn{4}{|c|}{ CD10 } & \multicolumn{4}{|c|}{ CD34 } \\
\hline & Stromal & $\%$ & Tumor & $\%$ & Stromal & $\%$ & Tumor & $\%$ & Stromal & $\%$ & Tumor & $\%$ \\
\hline$(0)$ & 8 & $40 \%$ & 0 & $0 \%$ & 12 & $60 \%$ & 9 & $45 \%$ & 6 & $30 \%$ & 20 & $100 \%$ \\
\hline$(1+)$ & 7 & $35 \%$ & 5 & $25 \%$ & 7 & $35 \%$ & 6 & $30 \%$ & 10 & $50 \%$ & 0 & $0 \%$ \\
\hline$(2+)$ & 5 & $25 \%$ & 15 & $75 \%$ & 1 & $5 \%$ & 5 & $25 \%$ & 4 & $20 \%$ & 0 & $0 \%$ \\
\hline Total & 20 & $100 \%$ & 20 & $100 \%$ & 20 & $100 \%$ & 20 & $100 \%$ & 20 & $100 \%$ & 20 & 100 \\
\hline
\end{tabular}


Table 2. Expression of CD10, Bcl-2 and CD34 in trichoepithelioma.

\begin{tabular}{ccccccccccccc}
\hline Trichoepithelioma & \multicolumn{4}{c}{ Bcl-2 } & \multicolumn{1}{c}{ CD10 } & \multicolumn{4}{c}{ CD34 } \\
Immune reactivity & Stromal & $\%$ & Tumor & $\%$ & Stromal & $\%$ & Tumor & $\%$ & Stromal & $\%$ & Tumor & $\%$ \\
\hline$(0)$ & 8 & $66.6 \%$ & 0 & $0 \%$ & 5 & $41.6 \%$ & 7 & $58.3 \%$ & 2 & $16.6 \%$ & 12 & $100 \%$ \\
$(1+)$ & 2 & $16.6 \%$ & 5 & $41.6 \%$ & 5 & $41.6 \%$ & 4 & $33.3 \%$ & 6 & $50 \%$ & 0 & $0 \%$ \\
$(2+)$ & 2 & $16.6 \%$ & 7 & $58.3 \%$ & 2 & $16.6 \%$ & 1 & $8.3 \%$ & 4 & $33.3 \%$ & 0 & $0 \%$ \\
Total & 12 & $100 \%$ & 12 & $100 \%$ & 12 & $100 \%$ & 12 & $100 \%$ & 12 & $100 \%$ & 12 & $100 \%$ \\
\hline
\end{tabular}

Table 3. Expression of CD10, Bcl-2 and CD34 in BCC.

\begin{tabular}{ccccccc}
\hline BCC & \multicolumn{2}{c}{ Bcl-2 } & \multicolumn{2}{c}{ CD10 } & \multicolumn{2}{c}{ CD34 } \\
\hline Intensity & Stromal cell & Tumor cell & Stromal cell & Tumor cell & Stromal cell & Tumor cell \\
\hline Positive & 12 & 20 & 8 & 11 & 14 & 0 \\
Negative & 8 & 0 & 12 & 9 & 6 & 20 \\
Total & 20 & 20 & 20 & 20 & 20 & 20 \\
P-value & 0.2517 & $<0.0001$ & 0.2517 & 0.4119 & 0.0577 & $<0.0001$ \\
\hline
\end{tabular}

${ }^{*}$ P-value $<0.05$ is significant. So, Bcl2 staining is significant in tumor cells and insignificant in stromal cells, CD34 staining is significant in tumor cells and insignificant in stromal cells, and CD10 staining is insignificant in both tumor and stromal cells.

Table 4. Expression of CD10, Bcl-2 and CD34 in trichoepithelioma.

\begin{tabular}{ccccccc}
\hline Trichoepithelioma & \multicolumn{2}{c}{ Bcl-2 } & \multicolumn{2}{c}{ CD10 } & \multicolumn{2}{c}{ CD34 } \\
\hline Intensity & Stromal cell & Tumor cell & Stromal cell & Tumor cell & Stromal cell & Tumor cell \\
\hline Positive & 4 & 12 & 7 & 5 & 10 & 0 \\
Negative & 8 & 0 & 5 & 7 & 2 & 12 \\
Total & 12 & 12 & 12 & 12 & 0.0193 & 0.0002 \\
P-value & 0.1938 & 0.0002 & 0.3872 & 0.3872 & 0.03 \\
\hline
\end{tabular}

So, Bcl2 staining is significant in tumor cells and insignificant in stromal cells, CD34 staining is significant in tumor cells and stromal cells, and CD10 staining is insignificant in tumor cells and stromal cells.

Table 5. Expression of Bcl-2 in BCC vs trichoepithelioma.

\begin{tabular}{ccccccc}
\hline Bcl-2 & \multicolumn{3}{c}{ Stromal Cell } & \multicolumn{3}{c}{ Tumor Cell } \\
\hline Intensity & Positive & Negative & P-value & Positive & Negative & P-value \\
\hline BCC & 12 & 8 & 0.2517 & 20 & 0 & $<0.0001$ \\
Trichoepithelioma & 4 & 8 & 0.1938 & 12 & 0 & 0.0002 \\
\hline
\end{tabular}

"P-value $<0.05$ is significant, so, Bcl2 staining is significant in tumor cells of both BCC and TE, and insignificant in stromal cells of both BCC and TE.

Table 6. Expression of CD10 in BCC vs trichoepithelioma.

\begin{tabular}{ccccccc}
\hline CD10 & \multicolumn{3}{c}{ Stromal Cell } & \multicolumn{3}{c}{ Tumor Cell } \\
\hline Intensity & Positive & Negative & P-value & Positive & Negative & P-value \\
\hline BCC & 8 & 12 & 0.2517 & 11 & 9 & 0.4119 \\
Trichoepithelioma & 7 & 5 & 0.3872 & 5 & 7 & 0.3872 \\
\hline
\end{tabular}

CD10 staining is insignificant in both BCC and TE. 
We noted that Bcl-2 immunoreactivity in tumor cells was strong in both BCC and TE, but it is stronger in basal layer in TE (Figure 3) and diffuse in BCC (Figure 4 \& Figure 5) and. CD10 immunoreactivity was strong in peritumoral stromal cells and negative in tumor cells of TE (Figure 6) and stronger in basaloid cells of BCC (Figure 7), and CD34 immunoreactivity was stronger in stromal cells of TE (Figure 8) than BCC (Figure 9).

Table 7. Expression of CD34 in BCC vs trichoepithelioma.

\begin{tabular}{|c|c|c|c|c|c|c|}
\hline \multirow{2}{*}{$\begin{array}{c}\text { CD34 } \\
\text { Intensity }\end{array}$} & \multicolumn{3}{|c|}{ Stromal cell } & \multicolumn{3}{|c|}{ Tumor cell } \\
\hline & Positive & Negative & P-value & Positive & Negative & P-value \\
\hline B.C.C & 14 & 6 & 0.0577 & 0 & 20 & $<0.0001$ \\
\hline Trichoepithelioma & 10 & 2 & 0.0193 & 0 & 12 & 0.0002 \\
\hline
\end{tabular}

CD34 staining is significant in tumor and stromal cells of TE, and significant in tumor cells of BCC.

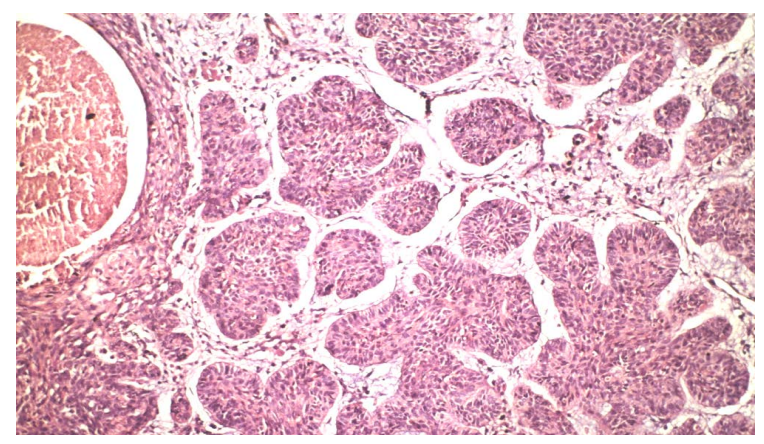

Figure 1. TE: Aggregates of basaloid cells in dermis with peripheral palisading, no clefts $(H \& E \times 150)$.

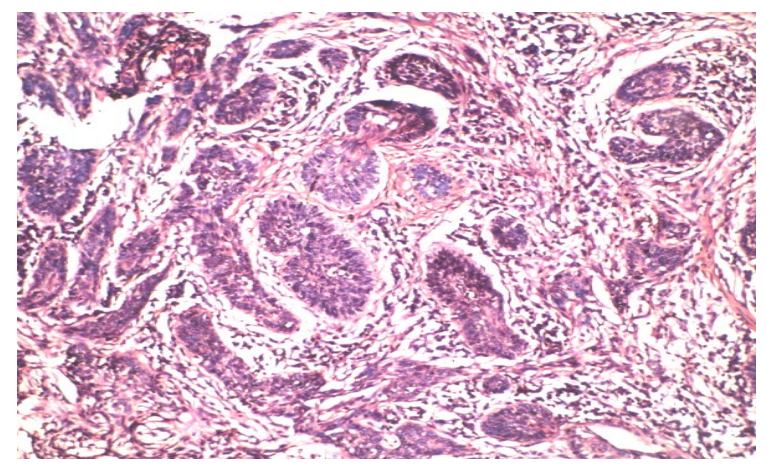

Figure 2. BCC: infiltrating nodules with surrounding cleft artifacts $(H \& E \times 135)$.

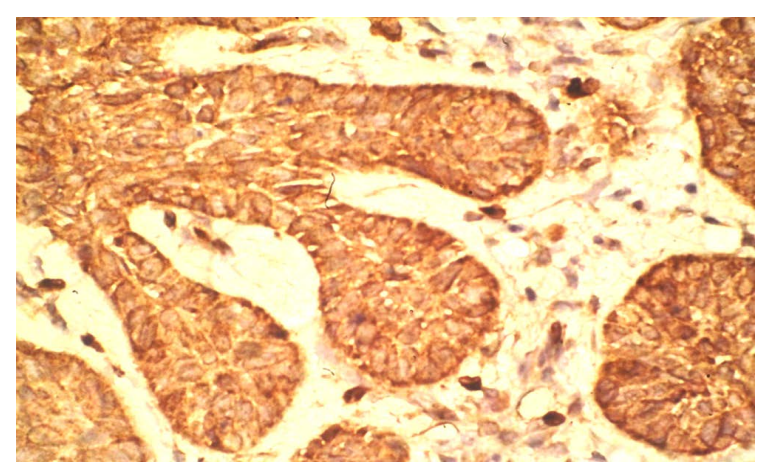

Figure 3. TE: stronger Bcl-2 staining of basaloid tumor cells, (DAB $\times 235)$. 


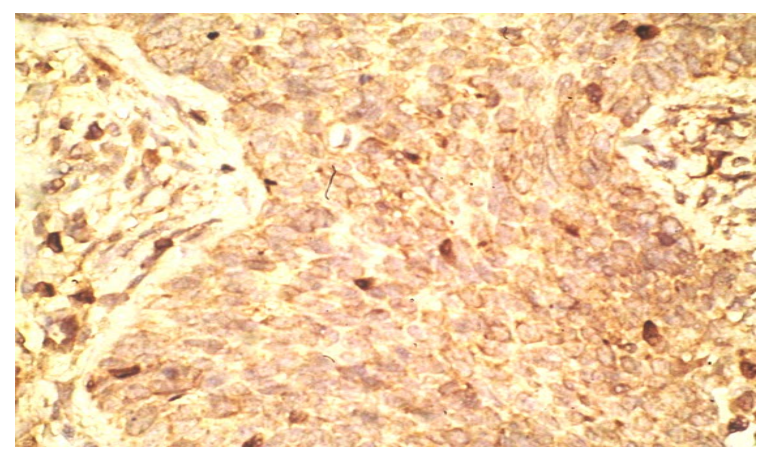

Figure 4. BCC: showing diffuse Bcl-2 staining of tumor cells $(\mathrm{DAB} \times 235)$.

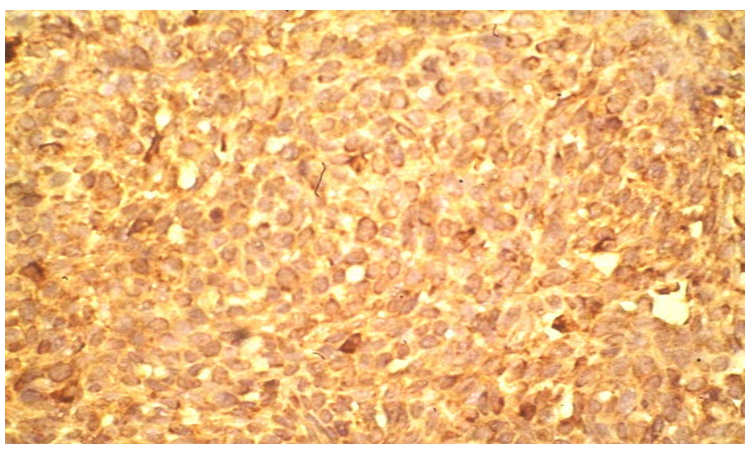

Figure 5. BCC: showing diffuse Bcl-2 staining of tumor cells (DAB ×360).

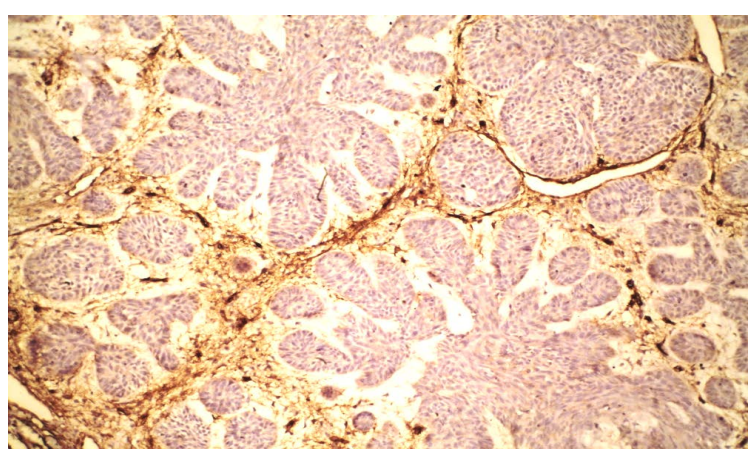

Figure 6. TE: CD10 positive stromal cells and negative tumor cells $(\mathrm{DAB} \times 135)$.

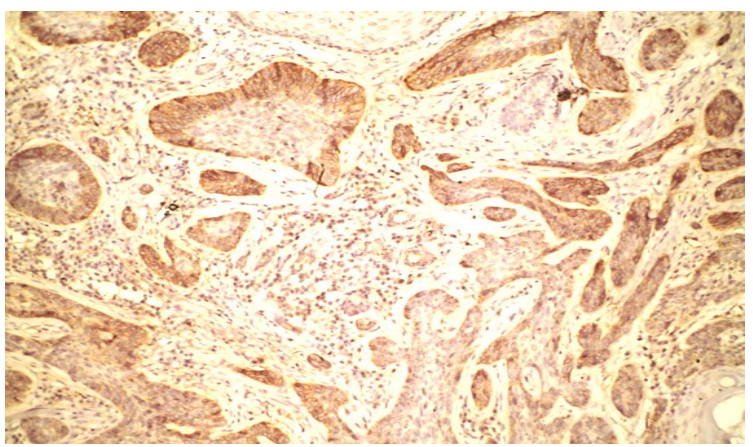

Figure 7. BCC: CD10 stronger staining of peripheral cells of nodules $(\mathrm{DAB} \times 235)$. 


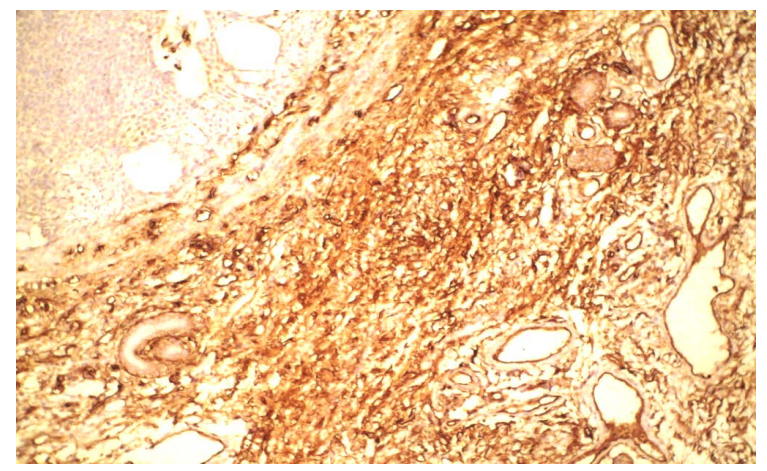

Figure 8. TE: strong CD34 staining of stromal cells, and negative tumor cells $(\mathrm{DAB} \times 360)$.

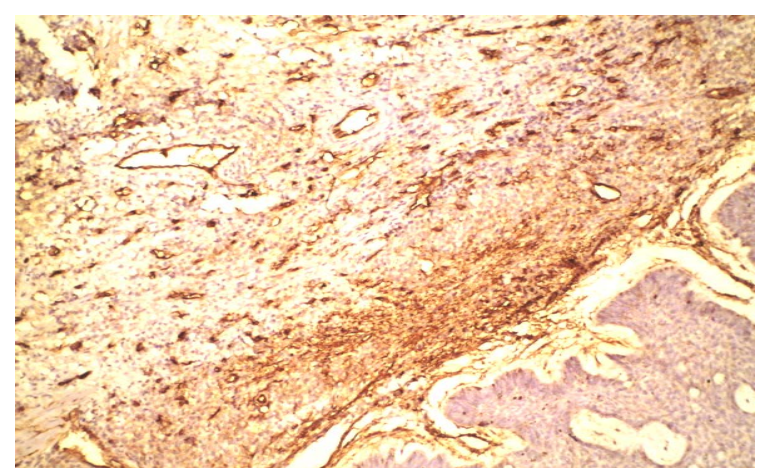

Figure 9. BCC: CD34 positive stromal cells and BV, and negative tumor cells $(\mathrm{DAB} \times 360)$.

\section{Discussion}

In the present study, we examined 20 BCC and 12 TE for Bcl-2, CD10 and CD34 expression to see the immunostaining pattern of BCC and TE and if these makers might aid in the differentiation between the two tumors.

The Bcl-2 positivity was seen in $60 \%$ and $100 \%$ of BCC stromal cells and tumor cells respectively, While there was $33.3 \%$ and $100 \% \mathrm{Bcl}-2$ expression in TE stromal cells and tumor cells respectively, and the pattern of staining is diffuse in BCC and stronger in basal layer in TE.

These findings are in agreement with some studies which stated that Bcl-2 diffusely stains the tumor nests in BCC while it stains the outermost cell layers in trichoepithelioma (Verhaegh et al., 1997 [17], and Smoller et al., 1994).

CD10 positivity was seen in $40 \%$ and 55\% of BCC stromal cells and tumor cells respectively while there was $58.3 \%$ and $41.6 \%$ CD10 expression in TE stromal cells and tumor cells respectively.

CD10 immunoreactivity in BCC, basaloid cells are strongly positive while in TE CD10 was strongly positive in peritumoral stromal cells with patchy staining of basaloid cells.

These findings are nearly in agreement with Sengul et al., (2010) which showed condensation of CD10-positive stromal cells around basaloid nests, which was statistically significant in differentiating TE from BCC. Conversely, CD10-positive basaloid cells were seen predominantly in BCC. No BCC cases demonstrated stromal expression alone in that study. The expression of CD10 by peritumoral stroma alone favored a diagnosis of TE, whereas staining of basaloid cells supported a diagnosis of BCC.

Wagoner et al., 2007 showed strong CD10 expression in the tumor cells of superficial BCC.

CD34 positivity was seen in 70\% of BCC stromal cells, and $83.3 \%$ of TE stromal cells, but tumor cells in both tumors showed no immunoreactivity.

The findings in this study, are in agreement with Sengul et al., (2010) which showed stromal expression of CD34 for 25 (83.3\%) of 30 cases in benign tumors of cutaneous appendages originating from hair follicle (BTCOHF) and 9 (30\%) of 21 (70\%) in BCC. While stromal expression of CD34 for BTCOHF was observing just the adjacent to the tumor islands; it was not like that for BCC. There was CD34 expressions in the sur- 
rounding stromas of BCCs with the adjacent zones which were not stained with CD34.

Illueca et al., 1998 [18] showed the usefulness of CD34 by showing the lack of CD34 expression by tumor stroma in BCC, but positive in TE.

The findings of this study are different from findings of Kirchmann et al., (1994) [19] which stained 19 cases of BCC and 16 cases of TE with CD34 in their study. They observed that while the spindle-shaped cells surrounding the islands of trichoepithelioma cells were focally strongly positive for CD34; surrounding the nests of tumor cells were negative in all basal cell carcinomas. So they suggested that, CD34 staining pattern differentiates between trichoepithelioma and basal cell carcinoma.

The findings of this study are different from findings of Naeyaert et al., (2001) which compared the CD34 staining patterns of TE with (fibroepithelioma) and nodular BCC. They also did not detect the peritumoral stromal expression of CD34 in those variants of BCC.

\section{Conclusion}

In conclusion we can suggest that bcl-2, CD10, and CD34 are useful markers in differentiation between BCC and TE. Positive immunostaining for bcl-2 tends to be diffuse in BCC, whereas it is peripheral in trichoepithelioma. Positive immunostaining for CD10 in stromal cells around basaloid nests favors TE over BCC. In addition, CD34 is found to be more positive in the stroma of trichoepithelioma than BCC and absent in tumor cells of both tumors. These findings may prove to be of diagnostic help in distinguishing borderline cases, and also offer some possible explanations for the biological differences between these neoplasms.

\section{References}

[1] Weedon, D. (2010) Tumors of the Epidermis, Chapter 31. In: Houston, M., Davie, B. and Lowsen, K., Eds., Weedon's Skin Pathology, 3rd Edition, Elsevier, Churchill Livingstone, 682-685.

[2] Crowson, A.N. (2006) Basal Cell Carcinoma: Biology, Morphology and Clinical Implications. Modern Pathology, 19, S127-S147.

[3] Cotton, D. (1991) Troublesome Tumors. 1: Adnexal Tumors of the Skin. Journal of Clinical Pathology, 44, 543-548. http://dx.doi.org/10.1136/jcp.44.7.543

[4] Sengul, D., Sengul, I., Astarci, M.H., Ustun, H. and Mocan, G. (2010) CD10 for the Distinct Differential Diagnosis of Basal Cell Carcinoma and Benign Tumors of Cutaneous Appendages Originating from Hair Follicle. Polish Journal of Pathology, 61, 140-146.

[5] Pham, T.T., Selim, M.A., Burchette Jr., J.L., Madden, J., Turner, J. and Herman, C. (2006) CD10 Expression in Trichoepithelioma and Basal Cell Carcinoma. Journal of Cutaneous Pathology, 33, 123-128. http://dx.doi.org/10.1111/j.0303-6987.2006.00283.x

[6] Dong, H.Y., Gorczyca, W., Liu, Z., Tsang, P., Wu, C.D., Cohen, P., et al. (2003) B-cell Lymphomas with Co-Expression of CD5 and CD10. American Journal of Clinical Pathology, 119, 218-230. http://dx.doi.org/10.1309/U98ADVKUC26R2RJA

[7] Takahara, M., Chen, S., Kido, M., Takeuchi, S., Uchi, H., Tu, Y., et al. (2009) Stromal CD10 Expression, as Well as Increased Dermal Macrophages and Decreased Langerhans Cells, Are Associated with Malignant Transformation of Keratinocytes. Journal of Cutaneous Pathology, 36, 668-674.

[8] Wagoner, J., Keehn, C. and Morgan, M.B. (2007) CD-10 Immunostaining Differentiates Superficial Basal Cell Carcinoma from Cutaneous Squamous Cell Carcinoma. American Journal of Dermatopathology, 29, 555-558. http://dx.doi.org/10.1097/DAD.0b013e3181596978

[9] Cerroni, L. and Kerl, H. (1994) Aberrant Bcl-2 Protein Expression Provides a Possible Mechanism of Neoplastic Cell Growth in Cutaneous Basal Cell Carcinoma. Journal of Cutaneous Pathology, 21, 398-403. http://dx.doi.org/10.1111/j.1600-0560.1994.tb00279.x

[10] Crowson, A.N., Magro, C.M., Kadin, M.E. and Stranc, M. (1996) Differential Expression of Bcl-2 Oncogene in Human Basal Cell Carcinoma. Human Pathology, 27, 355-359. http://dx.doi.org/10.1016/S0046-8177(96)90108-2

[11] Smoller, B.R., Van De Rijn, M., Lebrun, D. and Warnke, R.A. (1994) Bcl-2 Expression Reliably Distinguishes Trichoepitheliomas from Basal Cell Carcinomas. British Journal of Dermatology, 131, 28-31. http://dx.doi.org/10.1111/j.1365-2133.1994.tb08453.x

[12] Mills, A.E. (1997) Solar Keratosis Can Be Distinguished from Superficial Basal Cell Carcinoma by Expression of Bcl-2. American Journal of Dermatopathology, 19, 443-445. http://dx.doi.org/10.1097/00000372-199710000-00002

[13] Kanitakis, J. (1999) Expression of the Hair Stem Cell-Specific Keratin 15 Pillar Tumors of the Skin. European Journal 
of Dermatology, 9, 363-365.

[14] Naeyaert, J.M., Pauwels, C., Geerts, M.L., et al. (2001) CD-34 and Ki-67 Staining Patterns of Basaloid Follicular Hamartoma Are Different from Those in Fibroepithelioma of Pinkus and Other Variants of Basal Cell Carcinoma. Journal of Cutaneous Pathology, 28, 538-541. http://dx.doi.org/10.1034/j.1600-0560.2001.281008.x

[15] Nickoloff, B.J. (1991) The Human Progenitor Cell Antigen (CD34) Is Localized on Endothelial Cells, Dermal Dendritic Cells, and Perifollicular Cells in formalin-Fixed Normal Skin, and on Proliferating Endothelial Cells and Stromal spindle-Shaped Cells in Kaposi’s Sarcoma. Arch Dermatopthol, 127, 523-529. http://dx.doi.org/10.1001/archderm.1991.04510010091009

[16] Yada, K., Kashima, K., Daa, T., Kitano, S., Fujiwara, S. and Yokoyama, S. (2004) Expression of CD10 in Basal Cell Carcinoma. American Journal of Dermatopathology, 26, 463-471. http://dx.doi.org/10.1097/00000372-200412000-00004

[17] Verhaegh, M.E., Arends, J.W., Majoie, I.M., Hoekzema, R. and Neumann, H.A. (1997) Transforming Growth Factor-Beta and Bcl-2 Distribution Patterns Distinguish Trichoepithelioma from Basal Cell Carcinoma. Dermatologic Surgery, 23, 695-700. http://dx.doi.org/10.1111/j.1524-4725.1997.tb00392.x

[18] Illueca, C., Monteagudo, C., Revert, A. and Llombart-Bosch, A. (1998) Diagnostic Value of CD34 Immunostaining in Desmoplastic Trichilemmoma. Journal of Cutaneous Pathology, 25, 435-439. http://dx.doi.org/10.1111/j.1600-0560.1998.tb01770.x

[19] Kirchmann, T.T., Prieto, V.G. and Smoller, B.R. (1994) CD34 Staining Pattern Distinguishes Basal Cell Carcinoma from Trichoepitelioma. Arch Dermatopthol, 130, 589-592. http://dx.doi.org/10.1001/archderm.1994.01690050057008 
Scientific Research Publishing (SCIRP) is one of the largest Open Access journal publishers. It is currently publishing more than 200 open access, online, peer-reviewed journals covering a wide range of academic disciplines. SCIRP serves the worldwide academic communities and contributes to the progress and application of science with its publication.

Other selected journals from SCIRP are listed as below. Submit your manuscript to us via either submit@scirp.org or Online Submission Portal.
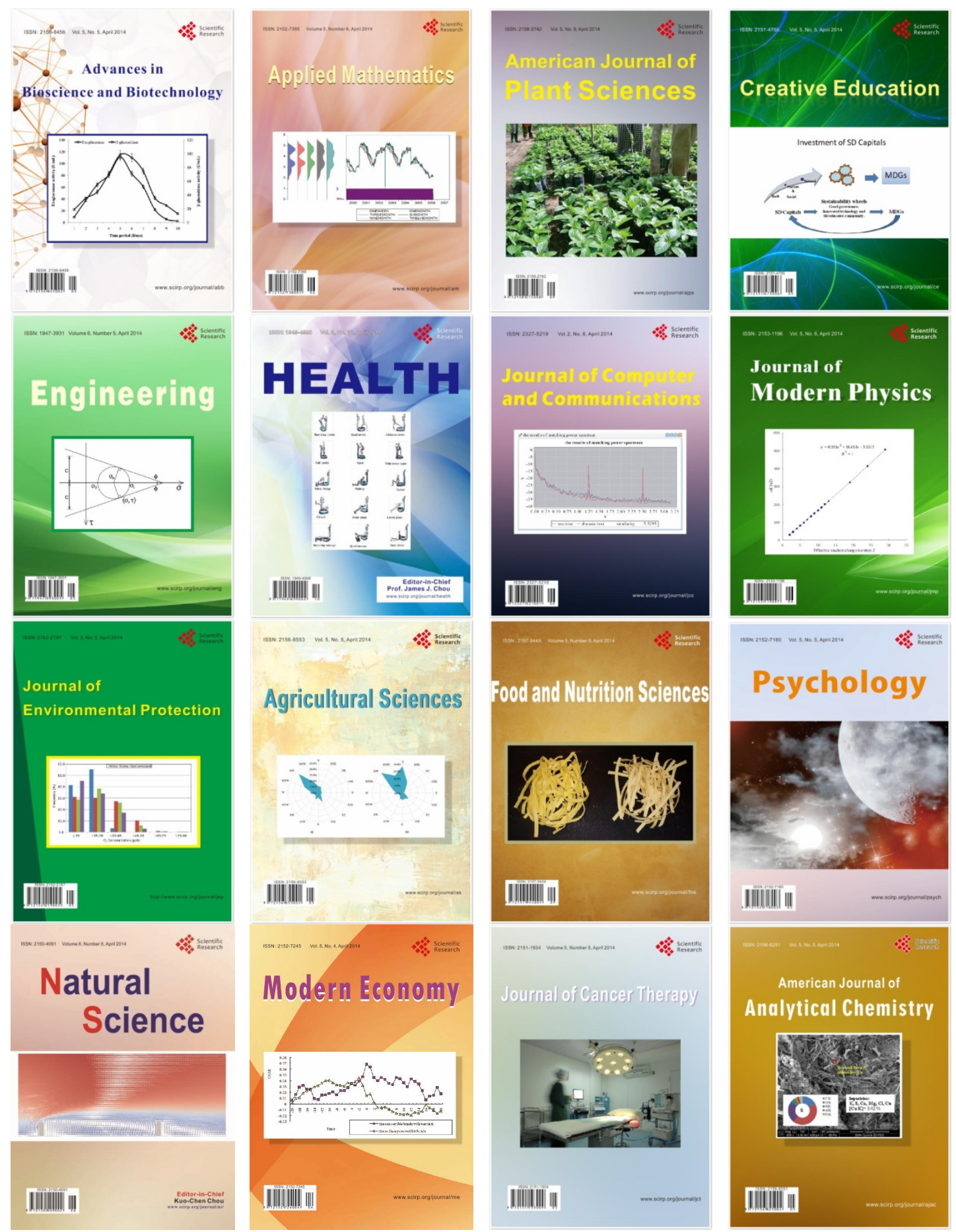